\title{
Hot wall growth and properties of lead telluride films doped by germanium and gallium
}

\author{
G.V. Lashkarev ${ }^{*}$, M.V. Radchenko ${ }^{1}$, E.I. Slynko ${ }^{1}$, V.N. Vodopiyanov ${ }^{1}$, V.V. Asotsky ${ }^{1}$, \\ V.M. Kaminsky ${ }^{1}$, G.V. Beketov ${ }^{2}$, E.V. Rengevich ${ }^{2}$ \\ ${ }^{1}$ Institute for Problems of Material Science, Ukrainian National Academy of \\ Sciences, Krzhizhanovskogo str.3, 03142 Kyiv, Ukraine \\ Phone: (044) 444-3228; Fax: (044) 444-2131; e-mail: lashk@ipms.kiev.ua \\ ${ }^{2}$ Institute for Semiconductor Physics, Ukrainian National Academy of \\ Sciences, pr. Nauki 45, 252650 Kyiv, Ukraine \\ Phone : (044)265-5749; Fax: (044) 265-8344; e-mail:torch@opto.kiev.ua
}

\begin{abstract}
The researches results of films $(\mathrm{PbTe})_{1-\mathrm{y}}(\mathrm{GaTe})_{\mathrm{y}}$ and $\left(\mathrm{Pb}_{1-\mathrm{x}} \mathrm{Ge}_{\mathrm{x}} \mathrm{Te}\right)_{1-\mathrm{y}}(\mathrm{GaTe})_{\mathrm{y}}$ of $n$-type conductivity with carrier concentration within $\left(2 \cdot 10^{17} \div 9 \cdot 10^{18}\right) \mathrm{cm}^{-3}$ are represented. The films were growth by modified hot wall technology on barium fluoride substrate. A state of films surface was investigated by Atomic Force Microscope using both contact and taping modes. Hall coefficient, specific resistivity and thermoelectromotive force of films were measured in the temperature range 77-300 K. The investigation showed that the presence of germanium leads to an appearance of significant features on temperature dependencies of termoelectromotive force which are connected with phase transition of displacement type. Doping gallium leads to $n$-type conductivity of films which increases with impurity concentration. The ionization energies of $\mathrm{Ga}$ impurities levels $(n-\exp (-E / 2 k T))$ were within $3 \div 10 \mathrm{meV}$. The change of energy position and width of impurity level with increase of impurity concentration is established. The unusual protrusions on terraces of growth were discovered. The tops of protrusions can be considered as quantum dots. Inasmuch as composition of protrusions is expected to be distinguished from that of the terraces, they can create pieces of quantum wires.

Keywords: $\mathrm{A}^{\mathrm{IV}} \mathrm{B}^{\mathrm{IV}}$ semiconductors, method hot wall epitaxy, Hall coefficient, resistivity, thermoelectric power, ionization energy, atomic force microscope.
\end{abstract}

Paper received 29.03.00; revised manuscript received 21.04.00; accepted for publication 16.06.00.

\section{Introduction}

$\mathrm{A}^{\mathrm{IV}} \mathrm{B}^{\mathrm{IV}}$ semiconductors are important materials for infrared devices. They are more technologically suitable, uniform and stable in comparison with $\mathrm{A}^{\mathrm{II}} \mathrm{B}^{\mathrm{VI}}$ which nowadays are the basic materials for infrared applications.

The behaviour of gallium impurity in PbTe had been investigated during a long period of time. The authors revealed on ceramic samples that $\mathrm{Ga}$ creates resonance level in conduction band at $200 \mathrm{meV}$ above its bottom [1]. On polycrystal specimens [2] gallium level was discovered close to the middle of forbidden gap. $\operatorname{In} \operatorname{PbTe}(\mathrm{Ga})$ single crystals the level of Ga was observed by galvanomagnetic measurements at $130 \mathrm{meV}$ below the bottom of conduction band [3, 4] and at $140 \mathrm{meV}$ [5]. Ionization energy of the gallium level calculated from electrical measurements on films deposited by hot wall epitaxy (HWE) also had a magnitude of $130 \div 140 \mathrm{meV}$ [6].
Nowadays it is established that gallium impurity in $\mathrm{PbTe}$ creates deep levels in the forbidden gap which drastically modifies characteristics of the semiconductor. It leads to unusual effects including Fermi level stabilizing within a forbidden gap, carrier freeze-off, impurity optical absorption and low temperature persistent photoconductivity [3, 7]. Long time relaxation processes result in high photosensitivity of crystals and films. These processes were explained by creation of autolocalized barrier which divides localized and free states [6]. The properties of such centre are determined by the type of impurity atom. Gallium can exist in different charge electron states.

One can suppose that introduction of gallium into crystal lattice and its electronic state depend on the method of semiconductor material growth and parameters of a technological process [6]. Therefore, it was of interest to deposit Ga doped $\mathrm{PbTe}$ films by HWE which allows to grow rather perfect material. 


\section{G.V. Lashkarev et al.: Hot wall growth and properties of lead telluride films doped ...}

Germanium impurity that has low dimension in comparison with lead ion stimulates (as noncentral impurity) phase transition of ferroelectric type which was observed earlier only in bulk materials [8]. We know only limited number of works where PbTe films doped by Ge and deposited by MBE and HWE displays phase transition, but details are absent (look for example [9])

The main goal of the work is to clarify the influence of HWE technology on properties of PbTe films doped by germanium and gallium. Investigation of thermoelectric power (TP) was foreseen because it gives a lot of information about zone structure, nature of impurity centres and phase transitions of semiconductors [8,10-12].

\section{Experiment}

The films were grown by modified HWE method in vacuum chamber at pressure not worse than $10^{-5} \mathrm{~mm} \mathrm{Hg}$. The four zone furnace were used. It consists of hot wall tube and three vapour sources to evaporate semiconductor and doping components. Heating of substrates is carried out by a low inertial heater. The temperatures of all parts of facility were maintained in the range $300 \div 900^{\circ} \mathrm{C}$. Substrate temperatures were held within $430 \div 540^{\circ} \mathrm{C}$.

Fresh cleaved surfaces (111) of barium fluoride were used as substrates. The thickness of films was in the interval $6 \div 137 \mu \mathrm{m}$.

The growth process is carried out in the following order: 1) the achievement of required temperatures for all the heaters and temperature stabilization; 2) reconciliation of substrate with HWE tube; 3) deposition of film; 4) taking off the substrate.

The attempts to grow films doped by gallium out of initial material with different concentration of doping impurity were unsuccessful. In this case gallium concentration in films was sufficiently low in comparison with its content in the precursor. At increased temperatures gallium pushes lead out from initial material. The latter leads to $\mathrm{Pb}$ increase in a film with simultaneous enlargement of electron concentration. Therefore, evaporation of $\mathrm{PbTe}$ and GaTe from separate sources was used. To form rectangular film samples for electric measurements special screens were applied.

Crystal lattice identification was carried out by XRD. The lattice period is practically the same as in bulk material. The films are single crystal type. The angles of block misorientation are within $3 \div 3.3$ minutes, dimensions of regions of coherent scattering are in the interval $(0.5 \div 0.64) \mu \mathrm{m}$, nonuniformity of interplay distances was about $(0.49 \div 0.74) \mu \mathrm{m}$. These data confirm high structure perfection of grown films.

Nanosize surface morphology of deposited films was studied by Atomic Force Microscope (AFM) Dimension $^{\mathrm{TM}} 3000$ (Digital Instruments) using both contact and tapping modes. Commercially available silicon nitride probes DNP ${ }^{\mathrm{TM}}$ for contact mode with nominal tip radii $\sim 20 \mathrm{~nm}$ were used. Tapping mode imaging was performed with TESP ${ }^{\mathrm{TM}}$ silicon probes $(r \sim 5 \div 10 \mathrm{~nm})$. Usual investigations were performed in air at room temperature.
Hall coefficient (HC), specific resistivity and thermoelectric power (TP) of films were measured in the temperature range $77 \div 300 \mathrm{~K}$.

All investigated samples had $n$-type conductivity. Electron concentration was within $\left(2 \cdot 10^{17} \div 9 \cdot 10^{18}\right) \mathrm{cm}^{-3}$. Electron mobilities reached the values as high as $2 \cdot 10^{4} \mathrm{~cm}^{2} / \mathrm{V} \cdot \mathrm{s}$, which also testifies in favor of high quality of deposited films.

\section{Results}

\subsection{Electrical properties}

\subsection{1. $(\mathrm{PbTe})_{1-y}(\mathrm{GaTe})_{y}$}

Electrical characteristics of samples $\mathrm{PbTe:Ga}$ are represented in Table 1. HC temperature dependencies are represented in Fig. 1. One can see a drop of $H C$ with temperature increase. For the most of samples a saturation of $R(T)$ at $T \geq 260 \mathrm{~K}$ is observed. Two exponential sections are seen in temperature dependencies $\lg R=\varphi(1 / T)$ (Fig. 2 ). They shift to higher temperatures at an increase of $\mathrm{Ga}$ content. Hall mobility of electrons and holes decrease with temperature in the interval $77 \div 300 \mathrm{~K}$ by the law $\mu \sim T^{-\beta}$.

As- deposited films are nonequillibrium. Their electrical characteristics change with time: carrier concentration increases, especially for holes, and mobility enlarges up to 6 times.

\subsection{2. $\left(P b_{1-x} G e T e\right)_{1-y}(G a T e)_{y}$}

Investigations of TP of PbGeTe:Ga films showed the existence of a feature on its temperature dependencies in the form of a bend. Electric characteristics and bend temperatures $T_{c}$, determined by the method as in [8], are represented in Table 2 . The typical curves are represented on Fig. 3.

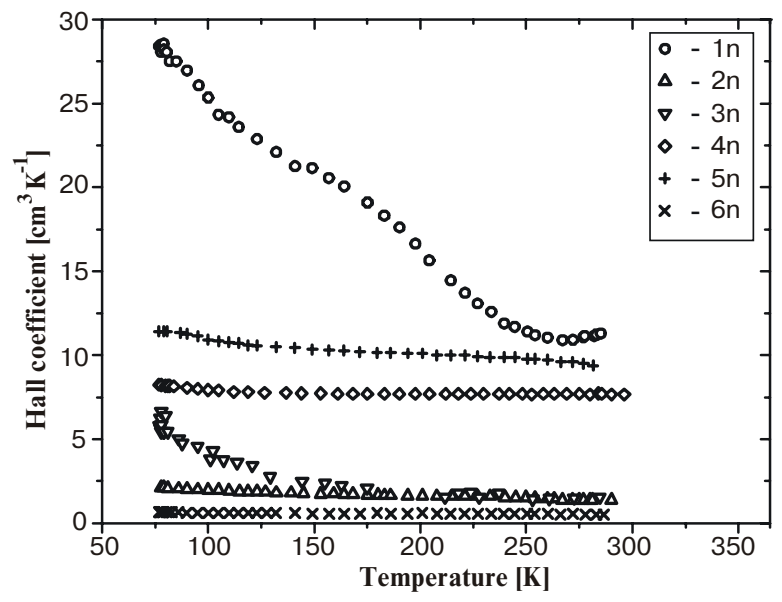

Fig. 1. Hall coefficient temperature dependencies of samples $(\mathrm{PbTe})_{1-\mathrm{y}}(\mathrm{GaTe})_{\mathrm{y}}$. 
G.V. Lashkarev et al.: Hot wall growth and properties of lead telluride films doped ...

Table 1. Electrical characteristics of samples $(\mathrm{PbTe})_{1-\mathrm{y}}(\mathrm{GaTe})_{\mathrm{y}}$

\begin{tabular}{llcccccc}
\hline \hline Sample & $\begin{array}{l}\text { Content of } \\
\mathrm{Ga}[\%]\end{array}$ & $\begin{array}{c}\text { Thickness } \\
{[\mu \mathrm{m}]}\end{array}$ & $\begin{array}{c}n_{77} 10^{17} \\
{\left[\mathrm{~cm}^{-3}\right]}\end{array}$ & $\begin{array}{c}\mu_{77} \\
{\left[\mathrm{~cm}^{2} \mathrm{~V}^{-1} \mathrm{~s}^{-1}\right]}\end{array}$ & $\beta$ & \multicolumn{2}{c}{ Ionization energy [meV] } \\
$\Delta E_{1}$ & $\Delta E_{2}$ \\
\hline $1 \mathrm{n}$ & 0.1 & 55 & $\sim 2.2$ & 7600 & 2.82 & 12 & 55 \\
\hline $2 \mathrm{n}$ & 0.15 & 15 & $\sim 30$ & 22300 & 2.2 & 8 & 51 \\
\hline $3 \mathrm{n}$ & 0.3 & 41 & $\sim 9.8$ & 7500 & 2.9 & 20 & 32 \\
\hline $4 \mathrm{n}$ & 0.3 & 32 & $\sim 7.6$ & 22600 & 2.22 & 2 & \\
\hline $5 \mathrm{n}$ & 0.5 & 137 & $\sim 5.5$ & 21300 & 2.4 & 3 & 24 \\
\hline $6 \mathrm{n}$ & 1.0 & 38 & $\sim 94$ & 14000 & 2.15 & 3 & \\
\hline \hline
\end{tabular}

Table 2. Characterstics of samples $\left(\mathrm{Pb}_{1-\mathrm{x}} \mathrm{Ge}_{\mathrm{x}} \mathrm{Te}\right)_{1-\mathrm{y}}(\mathrm{GaTe})_{\mathrm{y}}$

\begin{tabular}{lcccccccc}
\hline \hline Sample & $x$ & $y$ & $\begin{array}{c}\text { Thickness } \\
{[\mu \mathrm{m}]}\end{array}$ & $\begin{array}{c}n_{77} 10^{18} \\
{\left[\mathrm{~cm}^{-3}\right]}\end{array}$ & $\begin{array}{c}\mu_{77} \\
{\left[\mathrm{~cm}^{2} \mathrm{~V}^{-1} \mathrm{~s}^{-1}\right]}\end{array}$ & $\begin{array}{l}T_{c} \\
{[\mathrm{~K}]}\end{array}$ & $\begin{array}{c}\text { Composition } x \\
\text { accordingly } \\
\text { standard curve }\end{array}$ & $\begin{array}{c}\text { Composition } \\
\text { of the charge }\end{array}$ \\
\hline $9 \mathrm{n}$ & 0.12 & 0.002 & 34.6 & 1 & 3800 & 242 & 0.118 & 0.12 \\
\hline $10 \mathrm{n}$ & 0.12 & 0.002 & 20 & 3.2 & 10000 & 234 & 0.115 & 0.12 \\
\hline $11 \mathrm{n}$ & 0.12 & 0.1 & 6.2 & 6.63 & 12000 & 220 & 0.098 & 0.12 \\
\hline \hline
\end{tabular}

\subsection{Researches of films morphology by AFM}

One can see sphere like particles probably of gallium (dimensions are $95 \div 120 \mathrm{~nm}$ ) on the sample surfaces which can be removed by several scans of probe. After particles removing, unusual protrusions on terraces of growth can be visible (Fig. 4) under their position. These protrusions are probably connected with more prompt growth in comparison with the medium velocity of the terrace growth. Protrusions are not connected with definite crystallographic directions and are distributed perpendicular to the terraces lines.

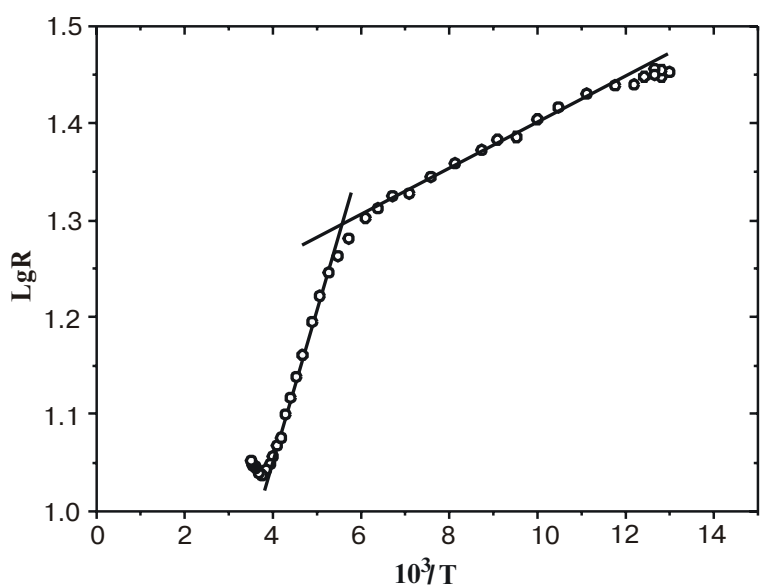

Fig. 2. Typical temperature dependence $\lg R=\varphi(1 / T)$ (sample $1 n$ ).

$S Q O, 3(3), 2000$
A situation is possible when composition of protrusions distinguishes from the composition of terraces that can increase the growth velocity of its parts and create pieces of quantum wires. Perhaps gallium particles can play a role of getter for matrix substance catching its molecules and increasing the velocity of terrace growth in the region of particles disposition. Along the perimeter of protrusion, more small particles $(\sim 40 \mathrm{~nm})$ in some cases can be observed.

Researches of epitaxial undoped PbTe films showed a presence of sphere-like particles of $\sim 40 \div 60 \mathrm{~nm}$ on the top of protrusions (Fig. 5). The nature of these particles

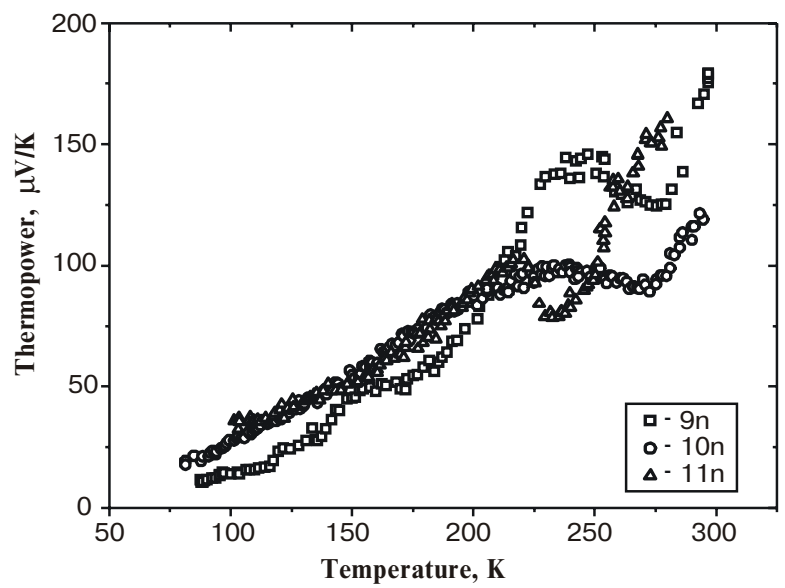

Fig. 3. Typical TP temperature dependencies of samples $\left(\mathrm{Pb}_{1-\mathrm{x}} \mathrm{Ge}_{\mathrm{x}} \mathrm{Te}\right)_{1-\mathrm{y}}(\mathrm{GaTe})_{\mathrm{y}}$. 


\section{G.V. Lashkarev et al.: Hot wall growth and properties of lead telluride films doped ...}

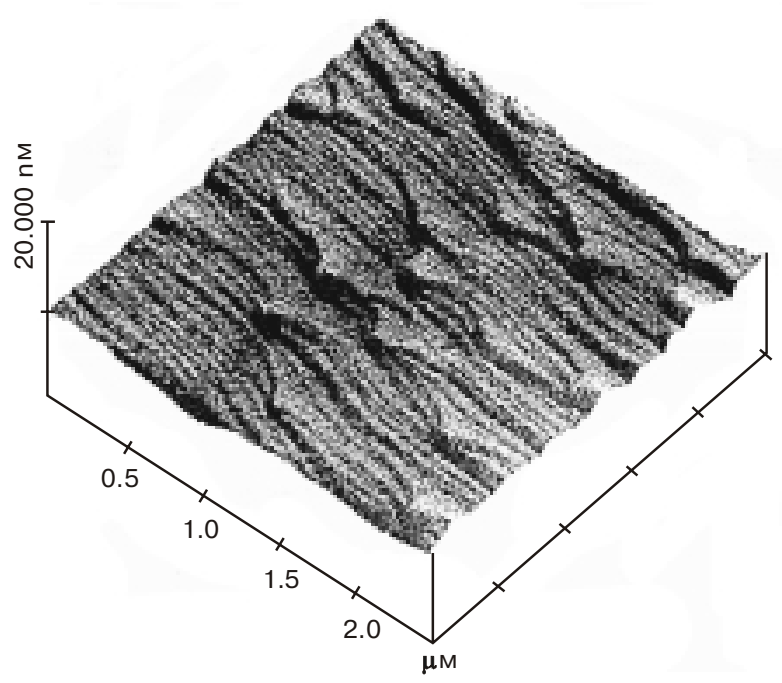

Fig. 4. AFM image of $\left(\mathrm{Pb}_{1-\mathrm{x}} \mathrm{Ge}_{\mathrm{x}} \mathrm{Te}\right)_{1-\mathrm{y}}(\mathrm{GaTe})_{\mathrm{y}}$. film after scans of probe.

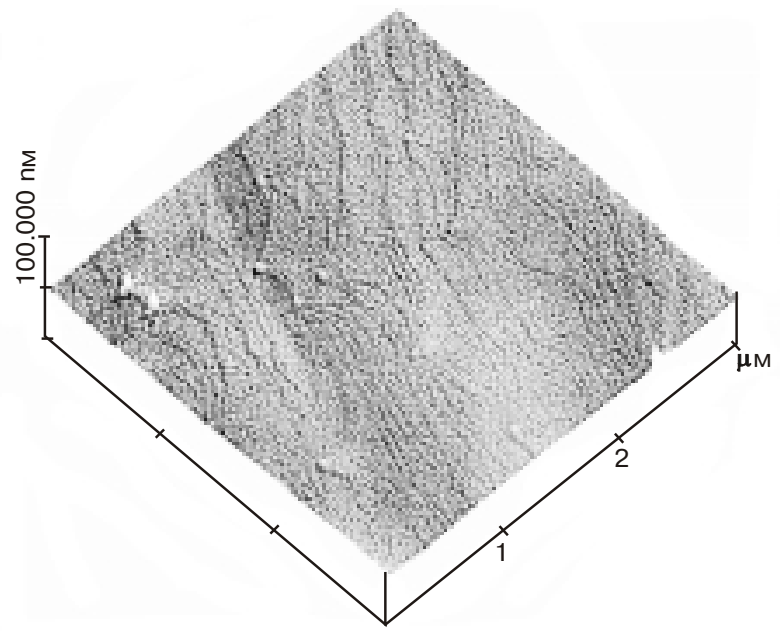

Fig. 5. AFM image of undoped PbTe films.

is unknown. It points out, that mechanisms of protrusion growth are a little bit different in both cases. The top of protrusion can be considered as a quantum dot.

Investigations of cleaved $\mathrm{BaF}_{2}$ crystals showed an absence of any specific formations that can be sources of protrusions. It means that protrusions appear as a result of growth features of parts of terraces and are not connected with substrate morphology .

Besides that there were several cases when in vicinity of extended defect the growth is observed only on one side of defect elevating growing terrace over it.

\section{Discussion}

\section{1. $(\mathrm{PbTe})_{1-y}(\mathrm{GaTe})_{y}$}

The existence of two exponential sections on HC temperature dependencies at low gallium concentration can be explained by the presence of two energy levels of gallium ions of different charge which are situated in forbidden gap. It is seen that, at increase of gallium content both at low and high temperatures, ionization energies decrease. It can be explained by changing an energy position and a width of impurity level with increasing impurity concentration. The difference of ionization energies between our data and the literature ones as well as between data of referred authors in energy position of gallium level is obviously due to different structure of impurity centres which form at different technologies.

Decrease of electron and hole mobilities with temperature is caused by scattering on acoustic and optical phonons. The values of $\beta\left(\mu \sim T^{\beta}\right)$ are represented in Table 1 . With an increasing gallium content, $\beta$ reduces, owing to enlargement of impurity scattering deposit.

\section{$4.2\left(P b_{1-x} G e_{x} T e\right)_{1-y}(G a T e)_{y}$}

We have shown in [8] that temperature dependence of TP for $\mathrm{Pb}_{1-\mathrm{x}} \mathrm{Ge}_{\mathrm{x}} \mathrm{Te}$ displays a feature at the temperature of phase transition $T_{c}$. The latter is connected with noncentral impurity of germanium, ion dimension of which is sufficiently less than that of $\mathrm{Pb}^{2+}$ ion. This results in displacement of germanium atom from the metal position that leads to creation of electric dipole. Correlation between dipole moments at temperature decrease leads to ferroelectric phase transition of displacement type. This results in rhombohedric distortion of cubic lattice ( $\mathrm{NaCl}$ type) at critical temperature and in change of electronic spectra. Increase of band gap $E_{g}$ below phase transition point leads to peculiarity of TP connected with strong dependence of current carriers effective mass on $E_{g}$ for narrow-gap semiconductors. Hence, for degenerated semiconductor (high concentration of carriers) TP manifests a break of linear temperature dependence. For nondegenerated case, TP displays a bend with maxima at $T=T_{c}[9,11]$.

Electron gas in investigated samples is nondegenerated at temperatures higher than $100 \mathrm{~K}$. Therefore, the feature of TP at phase transition has a form of a bend. The values of $T_{c}$ determined by the maxima of TP peculiarity are represented in Table 2 . Using $T_{c}$ dependence on $x$ [13] the film composition was determined and it was compared with the $x$ in initial material. One can see that Ge contents in the source and film are close. Inasmuch as determination of $\mathrm{Ge}$ content in a film is not easy the method of composition determination proposed by us appeared to be rather suitable. 


\section{G.V. Lashkarev et al.: Hot wall growth and properties of lead telluride films doped ...}

\section{Conclusion}

Thus some electric properties of $\mathrm{A}^{\mathrm{IV}} \mathrm{B}^{\mathrm{VI}}$ semiconductor films deposited by HWE technology are unusual and distinguish significantly from the same ones for samples prepared by other technologies.

\section{References}

1. A.N. Veis, V.I. Kaidanov, N.A. Kostyleva, R.B. Melnik, Yu.I Ukhanov, Impurity Gallium States in Lead Telluride // Fizika i tekhnika poluprovodnikov, 7(5), pp.928-930 (1973).

2. G.S. Bushmarina, B.F. Gruzinov, I.A. Drabkin, E.Ya. Lev, I.V. Nelson, On the Stabilization of a Fermi Level in GaDoped $\mathrm{Pb}_{1-\mathrm{x}} \mathrm{Ge}_{\mathrm{x}} \mathrm{Te}$ Alloys // Fizika i tekhnika poluprovodnikov, 11 (10), pp. 1874-1881 (1977).

3. B.A. Akimov, S.A. Belokon, Z.M. Dashevsky, K.N. Egorov, V.M. Lakeenkov, A.V. Nikorich, L.I. Ryabova, Energy Spectrum and Photoconductivity of $\mathrm{Pb}_{1-\mathrm{xX}} \mathrm{Mnx}_{\mathrm{X}} \mathrm{Te}(\mathrm{Ga})$ Solid Solutions // Fizika i tekhnika polupro-vodnikov, 25 (2), pp. 250253 (1991).

4. B.A. Akimov, N.B. Brandt, A.M. Gaskov V.P. Zlomanov, L.I. Ryabova, D.R. Khokhlov, Impurity States of $\mathrm{Ga}$ and Photoelectric Effects in $\mathrm{PbTe}(\mathrm{Ga})$ Alloys // Fizika i tekhnika poluprovodnikov, 17 (1), pp. 87-92 (1983).

5. F.F. Sizov, S.V. Plyatsko, V.M. Lakeenkov, Deep Levels in PbTe // Fizika i tekhnika poluprovodnikov, 19 (4), pp. 592596 (1985)

6. B.A. Akimov, A.V. Albul, V.Yu. Ilyin, M.Yu. Nekrasov, L.I. Ryabova, Photoconductivity Spectra and the Problem of
Impurity States in $\mathrm{PbTe}(\mathrm{Ga}) / /$ Fizika i tekhnika poluprovodnikov, 29 (11), pp. 2015-2023 (1995).

7. Yn.K. Vygranenko, V.V. Slynko, E.I. Slynko, Deep States in Gallium-Doped $\mathrm{Pb}_{1-\mathrm{x}} \mathrm{Sn}_{\mathrm{x}}$ Te Solid Solutions // Fizika i tekhnika poluprovodnikov, 27 (8), pp. 1387-1389 (1993).

8. G.V. Lashkarev, A.V. Brodovoy, S.D. Letyuchenko, M.V. Radchenko, E.I. Slynko, Magnetic Susceptibility and Kinetic Effects in $\mathrm{Pb}_{1-\mathrm{x}} \mathrm{Ge}_{\mathrm{x}} \mathrm{Te}(0.03 \leq x \leq 0.08)$ under Structure Phase Transition // Physics and Technics of Semiconductors 21 (10), pp. 1921-1923 (1987).

9. G. Bauer, H. Clemens, Physics and Applications of IV-VI Compound Quantum Well and Superlattice Structures // Semicond. Sci. Technol. 5, pp. S122-S130 (1990).

10. P. Lazarczyk, M.V. Radchenko, G.V. Lashkarev, T. Story, K. Dybko, R.R. Galazka, Determination of the Band Structure of PbSnMnTe Semimagnetic Semiconductors from Thermoelectric Power Studies // Semicond.Sci.Technol. 13, pp. 989-1001 (1998).

11. G.V. Lashkarev, M.V. Radchenko, V.B. Orletsky, E.I. Slynko, P.I. Starik, Special Features of Thermoelectric Phenomena in a $\mathrm{Pb}_{1-\mathrm{x}} \mathrm{Sn}_{\mathrm{x}} \mathrm{Te}(0 \leq x \leq 0.23)$ Solid Solutions at Low Temperatures // Fizika i tekhnika poluprovodnikov, 14 (3), pp. 490-495 (1980).

12. G.V. Lashkarev, R.O. Kikodze, M.V. Radchenko, E.I. Slynko, I.Z. Marchuk, Magnetoactive and Electroactive States of Manganese in a Narrow-Band $\mathrm{Pb}_{1-\mathrm{x}} \mathrm{Sn}_{\mathrm{x}} \mathrm{Te}$ Semiconductor $(0.18 \leq x \leq 0.23) / /$ Fizika i tekhnika poluprovodnikov, 13 (8), pp. 1548-1555 (1979).

13. S. Takaoka and K. Murase, Anomalous Resistivity Near the Ferroelectric Phase Transition in $(\mathrm{Pb}, \mathrm{Ge}, \mathrm{Sn}) \mathrm{Te}$ Alloy Semiconductors // Phys. Rev.B, 20 (7), pp. 2823-2833 (1979). 